\title{
The Use of Collagen with High Concentration in Cartilage Tissue Engineering by Means of 3D-Bioprinting
}

\author{
E. V. Isaeva ${ }^{a}$ *, E. E. Beketov ${ }^{a}$, V. V. Yuzhakov ${ }^{a}$, N. V. Arguchinskaya ${ }^{a}$, A. A. Kisel $^{a}$, E. P. Malakhov ${ }^{a}$, \\ T. S. Lagoda ${ }^{a}$, N. D. Yakovleva ${ }^{a}$, P. V. Shegai ${ }^{b}$, S. A. Ivanov ${ }^{a}$, and A. D. Kaprin ${ }^{b}$ \\ ${ }^{a}$ Tsyb MRRC-Branch of the National Medical Research Radiological Center of the Ministry of Health \\ of the Russian Federation, Obninsk, 249036 Russia \\ ${ }^{b}$ National Medical Research Radiological Center of the Ministry of Health of the Russian Federation, Obninsk, 249036 Russia \\ *e-mail:e1esa@yandex.ru
}

Received October 26, 2020; revised November 24, 2020; accepted November 30, 2020

\begin{abstract}
D-bioprinting is a promising technology for a tissue scaffold fabrication in the case of damaged tissue/organ replacement. Collagen is one of the most appropriate hydrogel for the purpose, due to its exceptional biocompatibility. However, the use of collagen with conventionally low concentration makes bioprinting process difficult and does not provide its high accuracy. The purpose of the study was evaluation of suitability of collagen with high concentration in case of chondrocyte-laden scaffold fabrication via 3D-bioprinting for cartilage regeneration in vitro and in vivo. The results of the study showed that inherent porosity of $4 \%$ collagen was not enough for cell survival in the case of long-term incubation in vitro. With the beginning of the scaffold incubation, cell migration to the surface and out of the scaffold was observed. The residual cells died mostly within 4 weeks. As for in vivo study, in 2 weeks after implantation of the scaffold, a weak granulomatous inflammation was observed. In 6 weeks, a connective tissue was formed in the area of implantation. In the tissue, macrophages and groups of small cells with round nuclei were found. In accordance with morphological criteria, these cells could be considered as young chondrocytes. However, its amount was not enough to initiate the formation of cartilage.
\end{abstract}

Keywords: tissue engineering, 3D-bioprinting, scaffold, bio-ink, collagen, chondrocytes, histology, immunohistochemistry

DOI: $10.1134 / \mathrm{S} 1990519 X 21050059$

3D-bioprinting is an option for regenerative medicine and tissue engineering. It helps to form tissueengineered structures (scaffolds) of a strictly defined shape. In the result of printing process both the cells and other components could be distributed according to a certain pattern in order to imitate the microarchitecture of various human tissues. In accordance with some experts' opinions, 3D-bioprinting will change regenerative medicine vastly in the future (Nguyen et al., 2017). The base of the technology is "bioink"-biocompatible materials supplemented with living cells (stem or differentiated ones). Recently, both the bio-ink and the technologies related to bioprinting have been the subject of the intensive research. Based on the data already available, the main requirements for bio-ink could be formulated (Murphy and Atala, 2014; Kesti et al., 2015; Beketov et al., 2019; Zhang et al., 2019):

(1) Bio-ink must be compatible with certain types of cells and organisms, not cause cell death or an immune response, and have a positive effect on adhesion, proliferation, migration and functioning of both endogenous and exogenous cells;
(2) Bio-ink must be printable, provide a stable output of the material during the extrusion, be applied both to culture dishes and other surfaces (e.g., sacrificial hydrogel), and ensure timely polymerization;

(3) Biomaterials must have controlled degradation kinetics and non-toxic degradation products, since embedded cells have to be able to produce extracellular matrix proteins that define new tissue;

(4) Structures formed by the bio-ink must have good mechanical properties, which are necessary for the functioning of the structure.

Currently, studies aimed at restoration of cartilage and bone, as well as skin with the use of 3D-bioprinting have gained the stage of clinical trials (Murphy et al., 2020). Cartilage is characterized by a relatively simple structure with a low density of cells. It does not contain any blood vessels or nerves. This feature simplifies the fabrication of tissue-engineered constructions (Grogan et al., 2003; Murphy et al., 2020). The number of materials have already been used for the purpose: gelatin methacrylamide (Schuurman et al., 2013; Levato et al., 2017), collagen (Ren et al., 2016), polyethylene glycol dimethacrylate (Cui et al., 2012), 
alginate/nanocellulose (Nguyen et al., 2017), decellularized extracellular matrix of cartialge with polysaccharides: gellan and alginate (Kesti et al., 2015).

Collagen is a natural protein polymer. Its molecule is a right-handed helix of three $\alpha$-chains. The chains contain cell adhesion sites based on the arginine-glycine-aspartic acid (RGD) tripeptide (Chaisri et al., 2015). Molecular structure and mass, as well as temperature conditions affect collagen properties, determine its viscosity and, thus, hydrogel formation (Zhang et al., 2019). Collagen is a part of extracellular matrix and mainly resides in an connective tissue of animals and humans. Currently, 29 types of collagen have been described, which are encoded by more than 40 genes (Chaisri et al., 2015). However, more than $90 \%$ of all collagen is related to type I, II, III, and IV (Abraham et al., 2008). Collagen type I is involved in numerous physiological interactions, modulates cell proliferation, migration, differentiation, and specific gene expression (Liu et al., 2008). The collagen is characterized by biocompatibility, biodegradability, and low immunogenicity. Therefore, it is widely used for 3D-bioprinting (Liu et al., 2008; Osidak et al., 2019; Zhang et al., 2019).

Traditionally for the bio-ink based on collagen, low concentration of the hydrogel (up to 1\%) is used (Drobnik et al., 2019; Okubo et al., 2019). It is explained by the need of access of nutrients and gases to the cells in the scaffold. However, further development of 3D-bioprinting is aimed at increasing the printing accuracy and better preserving the geometric parameters of the scaffold, which requires the use of more viscous hydrogels (Skardal et al., 2015). One option is to use of higher concentrated collagen (Osidak et al., 2019). The aim of this study is to assess the suitability of high-concentration collagen for the fabrication of chondrocytes-laden scaffold by 3D-bioprinting for the restoration of cartilage in vitro and in vivo.

\section{MATERIALS AND METHODS Cells}

The cells were obtained from the xiphoid cartilage of two outbred white male rats (weight $300 \mathrm{~g}$, age 4 months). The cartilage was separated from the sternum (previously, all soft tissues were removed), cut into 3-4 $\mathrm{mm}$ thick pieces, washed twice with sterile PBS, and placed into $0.15 \%$ collagenase solution in DMEM medium. Tissue fragments were incubated at $37^{\circ} \mathrm{C}$ and $5 \% \mathrm{CO}_{2}$ for $\sim 20 \mathrm{~h}$ (MCO-5AC, Sanyo, Japan). After the incubation, for the final separation of the cells, the solution was stirred for $30 \mathrm{~min}$ on a magnetic stirrer (Biosan, Latvia), then the cells were precipitated for $5 \mathrm{~min}$ at $400 \mathrm{~g}$ (ELMI CM-6M, Latvia). To wash off the enzymes, the cell pellet was resuspended in the medium supplemented with $10 \%$ fetal calf serum (Biosera, France) and centrifuged again. The procedure was repeated twice. Afterwards, the cells were resuspended in the medium with serum. The suspension was stained with $0.4 \%$ trypan blue solution in PBS for cell viability estimation. The cell suspension $\left(\sim 450.000 \mathrm{~mL}^{-1}\right)$ was transferred into $25 \mathrm{~cm}^{2}$ flask (Corning, USA), the medium with $10 \%$ serum, penicillin-streptomycin, and glutamine was placed in the $\mathrm{CO}_{2}$-incubator for cell attachment and proliferation. In 48 hours, the medium was changed. The cells were cultivated until monolayer formation. For the experiment, cells of the $2^{\text {nd }}$ passage were used.

\section{Bio-ink}

Bio-ink were prepared using sterile pig atelocollagen type I according to the earlier described procedure (Osidak et al., 2019). On the day of the experiment, the cells were removed from the flasks with trypsinEDTA solution; after staining with trypan blue, the number of living cells was counted in hemocytometer, centrifuged (400 $\mathrm{g}, 5 \mathrm{~min}$ ), and resuspended in $0.25 \mathrm{~mL}$ of the medium without serum. The cell suspension in a volume of $0.25 \mathrm{~mL}$ was mixed with $0.25 \mathrm{~mL}$ of collagen buffer solution and kept for $10 \mathrm{~min}$ at $4^{\circ} \mathrm{C}$. This solution was mixed with $0.5 \mathrm{~mL}$ of collagen. Collagen concentration in bio-ink was $4 \%$. The bio-ink was kept at $4^{\circ} \mathrm{C}$ prior to the printing. The final cell concentration was $20 \times 10^{6} \mathrm{~mL}^{-1}$.

\section{Bioprinting}

Rokit Invivo 3D-bioprinter (South Korea) with software version 1.68 was used for the scaffold fabrication. Slicing of the model was performed in NewCreatorK 1.57.63. The hydrogel was in a glass "LuerLock" type syringe with an inner diameter of $8.24 \mathrm{~mm}$. The material was fed through a $21 \mathrm{G}$ needle (inner diameter $514 \mu \mathrm{m}$ ) with 0.5 inch length. The printing was carried out into sterile $60 \mathrm{~mm}$ Petri dishes (Corning, USA). The layer height was $386 \mu \mathrm{m}-75 \%$ of the nozzle diameter (Arguchinskaya et al., 2019). To obtain a stable filament, the printing was conducted with 1.5-fold material yield. The filling density was proportionally $(66 \%)$ reduced. Concentric printing algorithm was applied. The material yield on the first layer was increased by $30 \%$ to take into account the error in determining the base level. The printing speed was $5 \mathrm{~mm} / \mathrm{s}$. The dispenser temperature was $4^{\circ} \mathrm{C}$. RT was maintained at the printing table. Before the fabrication, the chamber of the printer was sterilized using a built-in UV lamp with a wavelength of $254 \mathrm{~nm}$. The scaffold dimensions was $4 \times 4 \times 4 \mathrm{~mm}$.

\section{In vitro Incubation}

After the printing process completion, Petri dishes with the scaffolds were filled with a warm medium. Composition of the medium: DMEM with glucose $4.5 \mathrm{~g} / \mathrm{L}, 10 \%$ fetal calf serum, $50 \mathrm{U} / \mu \mathrm{g} / \mathrm{mL}$ penicillinstreptomycin, $649 \mu \mathrm{g} / \mathrm{mL}$ glutamine, $100 \mathrm{ng} / \mathrm{mL}$ fibroblast growth factor, $100 \mathrm{ng} / \mathrm{mL}$ insulin-like 
growth factor I type, $10 \mathrm{ng} / \mathrm{mL}$ transforming growth factor $\beta 1$. The scaffolds were incubated under the standard cell culture conditions. The medium was changed twice a week.

\section{Animal Experiments}

The experiment was conducted in accordance with the general recommendations of A Tsyb MRRC committee for bioethics of experimental research on laboratory animals. One hour after the printing, two scaffolds were implanted into two outbred white male rats. All operations with animals were performed using inhalation ether anesthesia. The animals' hair were cut off in the area of the withers. The operating field was treated with a $70 \%$ ethanol solution. In the course of the wound suturing, the edges of the pocket were pulled together, the site of implantation was marked with a colored thread of suture material. The seam was treated with $3 \%$ hydrogen peroxide solution. The second suture was applied to the skin. The area was retreated with hydrogen peroxide. Additionally, medical glue was applied on top. For anesthesia purpose, $0.1 \mathrm{~mL}$ of a $0.5 \%$ solution of novocaine was injected into the withers in three places around the operating field. During the experiment, the rats were kept isolated from each other in single cages with free access to water and food. The surgical site was examined on a daily basis. The animals were euthanized after 2 and 6 weeks after the implantation, material was taken for histological examination.

\section{Histology and Immunohistochemistry}

The scaffolds were subjected to histological examination in $1 \mathrm{~h}, 2$ and 4 weeks after the printing. The biomaterial of the animals was examined in 2 and 6 weeks after implantation. Collagen scaffolds and tissue fragments were fixed for $24 \mathrm{~h}$ in Bouin's acidic liquid. After washing in 70\% ethanol, the standard histological procedures were performed, followed by its fixation in paraffin. Paraffin sections of $5 \mu \mathrm{m}$ thickness formed by microtome (Leica RM2235, Germany) were placed on silanized glasses (S3003, Dako, Denmark). For histological studies, dewaxed sections were stained with hematoxylin and eosin and Mowry's alcian blue. After dehydration in alcohols and clearing in xylene, the preparations were embedded in Canada balsam.

Immunohistochemical studies on serial sections were performed using polyclonal rabbit antibodies to nuclear antigen of proliferating cells-PCNA $(1: 100)$ and monoclonal rabbit antibodies to endothelial marker-adhesion molecule of platelet/endothelial cells-1-PECAM-1 (1:250). For immunovisualization of rabbit antibodies, goat antibodies to rabbit IgG conjugated with horseradish peroxidase $(1: 1000)$ were used. Solutions for immunohistochemistry were prepared in PBS.
The detection of antigens on histological sections was performed according to the basic requirements for immunoperoxidase methods. All antibodies and kits were preliminarily tested on a positive control of experimental material. The optimal conditions for immunostaining were determined by the ratio of the intensity of the immunopositive reaction to the background. According to the protocol of immunohistochemical studies, before applying primary antibodies to PCNA and CD31, dewaxed sections immersed in citrate buffer $(\mathrm{pH} 6.0)$ were heated in a microwave oven $(5 \mathrm{~min}, 720 \mathrm{~W})$. Endogenous peroxidase was blocked in 3\% hydrogen peroxide solution. The blocking buffer was supplemented with $2 \%$ serum of animal donors of second antibodies, $1 \%$ bovine serum albumin, and $0.1 \%$ Triton X-100. In a solution of primary antibodies, the preparations were incubated overnight in a humidifying chamber at $4^{\circ} \mathrm{C}$. After washing the preparations in PBS, secondary antibodies were applied to the sections for 1 hour at RT. Substrate peroxidase was detected using diaminobenzidine (Liquid $\mathrm{DAB}+$, DAKO, K3468). Cell nuclei were counterstained with Mayer's hematoxylin. Histological preparations were studied via Leica DM 1000 microscope (Germany) with Leica ICC50 HD camera (Germany).

\section{Reagents}

Acetone (Russia); Alcian blue (8GX, SigmaAldrich); bovine serum albumin (Santa Cruz, USA); Canada balsam (Merck, Germany); diaminobenzidine (Dako, Denmark); eosin (1\% alcohol solution) (BioVitrum, Russia); ether for anesthesia (Chimmed, Russia); fetal calf serum (Biosera, France); fibroblast growth factor (PanEko, Russia); formalin (for Bouin's liquid, 40\%) (BioVitrum, Russia); glutamine (PanEko, Russia); goat antibodies conjugated with horseradish peroxidase (ab205718) (Abcam, UK); goat serum (Sigma-Aldrich, USA); hydrogen peroxide (3\%) (Russia); chloroform (chemically pure) (Russia); insulin-like growth factor I type (IGF-1, SigmaAldrich); Mayer's hematoxylin (BioVitrum, Russia); medical ethanol (95\%, RFK, Russia); medical glue BF-6 (MPZ, Russia); monoclonal rabbit antibodies to CD31/PECAM-1 (ab182981) (Abcam, UK); novocaine (JSC Dalkhimpharm, Russia); paraffin medium (Histomix); PBS (pH 7.4, EKOservice, Russia); penicillin-streptomycin (PanEko, Russia); DMEM medium (glucose content $4.5 \mathrm{~g} / \mathrm{L}$ ); pig type I atelocollagen set with buffer solution $(80 \mathrm{mg} / \mathrm{mL}$, IMTEK, Russia); polyclonal rabbit antibodies to PCNA (PA527214, Invitrogen, USA); suture material (monocryl poliglecaprone 25, Ethicon, USA-Belgium); transforming growth factor $\beta 1$; trinitrophenol (for the preparation of Bouin's liquid, 1.3\%) (Sigma-Aldrich, USA); Triton X-100 (Sigma-Aldrich, USA); trypan blue (PanEko, Russia); trypsin-EDTA solution (PanEko, Russia); type II collagenase (Clostridium 


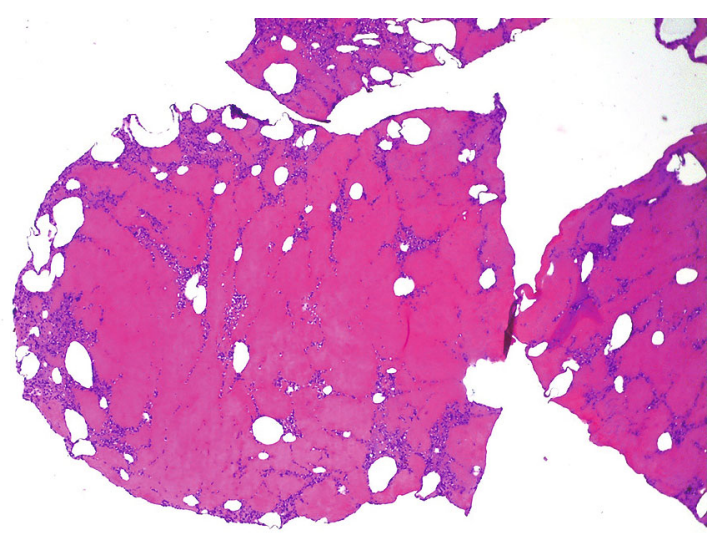

Fig. 1. Distribution of chondrocytes in collagen scaffold in $1 \mathrm{~h}$ after the printing. Staining with hematoxylin and eosin. Ob. $2.5 \times$.

histolyticum, $315 \mathrm{U} / \mathrm{mg}$ ) (PanEko, Russia); xylene (ortho) (analytical grade) (Russia).

\section{RESULTS}

\section{In vitro Study}

During the primary isolation of cells from the animal's cartilage using collagenase, its total number was relatively small. It was probably due to the age of the donors. The yield of living cells with the described isolation method was $86.4 \%$. The zero passage cells had quadratic shape and granular cytoplasm - the features of native chondrocytes. The cells formed a dense monolayer on the 7th day of cultivation. Viability of the 2nd passage cells used in the experiment was $99.9 \%$.

The cells in the collagen scaffold in 1 hour after the printing is shown in Fig. 1. The distribution of cells over the volume of the scaffold is uneven. The cells were concentrated mostly at air bubbles inside the structure and near the free surfaces of the scaffold. Within the next few days a massive migration of the cells from the scaffolds and their attachment to the bottom of the Petri dish was observed (Fig. 2). Later on the rate of the process decreased. In order to prevent the depletion of the nutrient medium by cells migrated from collagen structures, the scaffolds were transferred into new dishes.

By the second week of incubation, a decrease in size, deformation, and partial destruction of the scaffolds were observed (Fig. 3a). Uneven coloration of collagen at Fig. 3 is visible: there are lighter (loose) and dark (dense) areas. Probably, the density of collagen has changed due to destruction, as well as the action of cellular proteolytic enzymes. There were no air bubbles in the denser areas. The cells are concentrated in looser areas (Fig. 3b). Many cells were located on the surface of structure (Fig. 3c). The PCNA-positive reaction of the nuclei was observed only in individual cells (Fig. 3d), which probably indicates that the bulk

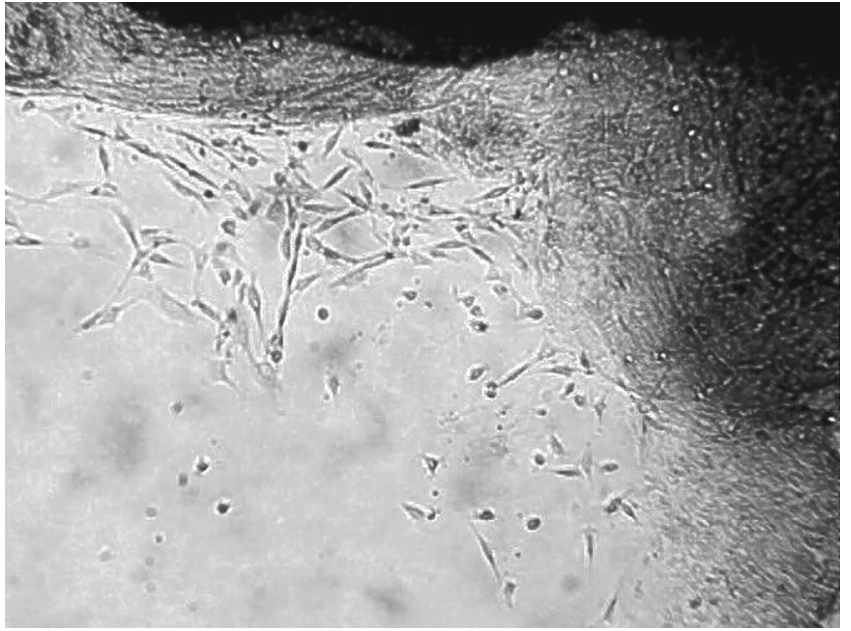

Fig. 2. Migration of chondrocytes from the scaffolds to the bottom of Petri dish in 1st day after the printing. Phase contrast, ob. $10 \times$.

of the cells were at rest. In the next 14 days the most of the cells in collagen scaffold have died.

In 28 days the scaffolds decreased in size and deformed (Fig. 4a), and cellular detritus was present (Fig. 4b). It is obvious that after 4 weeks of incubation only single cells stayed alive in the scaffolds (Figs. 4c, 4d).

\section{In vivo Study}

Histological examination showed that in 2 weeks after the implantation in some areas cellular detritus took the place. It was consisted of fragments of the scaffold, dead polymorphonuclear leukocytes and necrotic subcutaneous muscle fibers (Figs. 5a, 5b). A capsule of connective tissue was formed around the scaffold, which grew into collagen, dividing it into separate fragments (Fig. 6). Macrophages, apparently involved in the process of resorption of the biomaterial, as well as granulomas of foreign bodies were located around the blood vessels (Fig. 7). Granulomatous nodules surrounded by blood vessels contained a large number of cellular elements located around the scaffold fragments.

Immunohistochemical staining for CD-31 revealed numerous small blood vessels forming in the scaffold resorption zones (Fig. 8). A positive reaction of nuclei to PCNA was observed in connective tissue cells, vascular endothelium, and cellular elements of granulomas (Fig. 9). In the surrounding connective tissue, the presence of cellular elements with rounded nuclei and a narrow rim of cytoplasm (possibly chondrocytes) was noted. Thus, the results of the pathomorphological examination indicate that in 2 weeks after implantation of the scaffold, granulomatous inflammation with the destruction of the organic matrix by macrophages and giant cells is observed. 
(a)

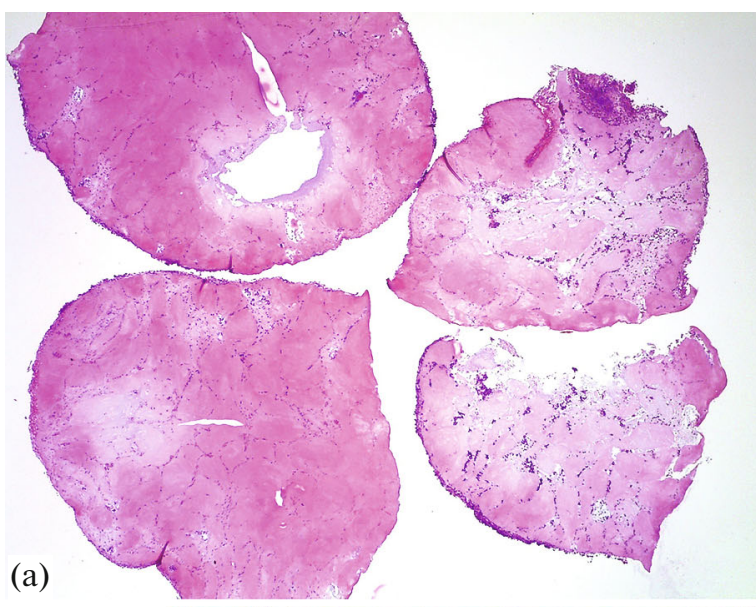

(c)

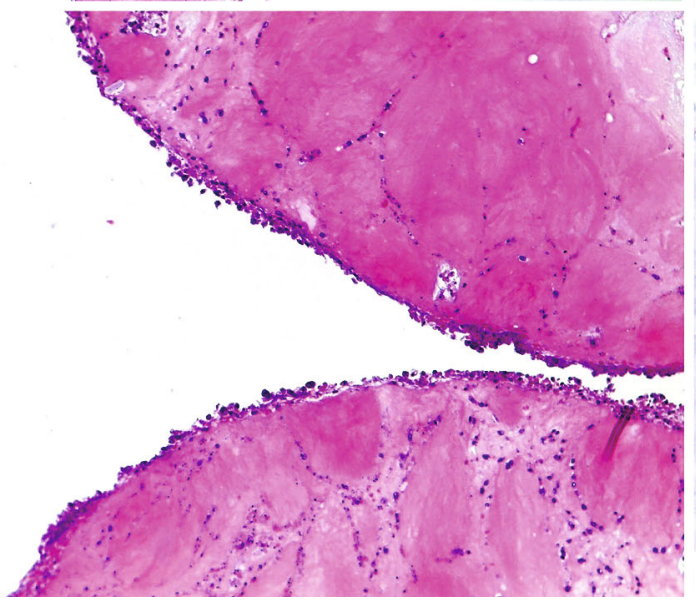

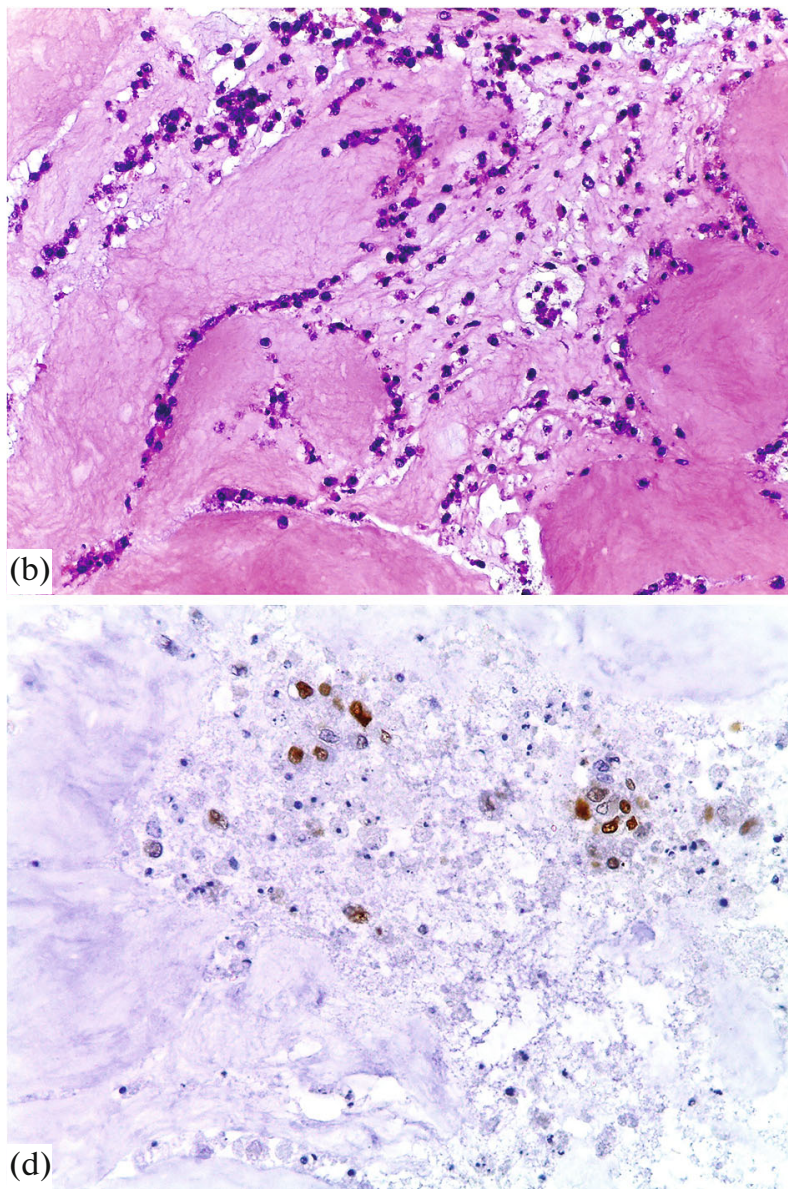

Fig. 3. Chondrocytes in tissue-engineered structures in 14 days after the printing. $(\mathrm{a}-\mathrm{c})$ Hematoxylin and eosin staining, (d) PCNA immunostaining. Ob.: (a) $2.5 \times$, (b) $20 \times$, (c) $10 \times$, (d) $40 \times$.

Within 6 weeks under the epidermis, connective tissue was formed (Fig. 10a), in which, next to the blood vessels, macrophages and groups of small cells with rounded nuclei were found. According to morphological criteria these cells correspond to young chondrocytes (Fig. 10b, c). The cytoplasm of these cells gave a positive reaction for glycosaminoglycans when stained with alcian blue (Fig. 10d). At the same time, these evidences of the formation of cartilage can be considered indirect and require further confirmation.

\section{DISCUSSION}

Three-dimensional culture of chondrocytes is considered preferable for the regeneration of cartilage (Okubo et al., 2019). The combination of 3D-cultivation with the addition of growth factors allows maintaining the specific phenotype of chondrocytes (Nguyen et al., 2017; Okubo et al., 2019), ensuring the synthesis and accumulation of extracellular matrix: proteoglycans and collagens (Grogan et al., 2003; Beketov et al., 2019). Three-dimensional cultivation conditions are created mainly with the help of scaffolds made of various materials, which serve as a sub- strate for cell attachment, survival and proliferation of cellular elements. Cell viability in artificial tissues depends on the efficiency of oxygen and nutrients supply. Limitations in metabolites transport in scaffolds is one of the most pronounced problem for the whole tissue engineering (Brown et al., 2007). Under static conditions of cultivation, diffusion is the main method of the transport. It is assumed that oxygen constantly enters the peripheral zones of a scaffold. Its concentration is proportional to the partial pressure of the gas and the coefficient of solubility in a medium (Brown et al., 2007). Since oxygen diffusion in artificial tissues is often slower than oxygen consumption, oxygen is a limiting factor for cell survival in scaffolds thicker than 100-200 $\mu \mathrm{m}$ (Malda et al., 2004). The availability of oxygen depends not only on the length of the diffusion distance but also on the density of the cells, since the ability of oxygen to diffuse through cells is much less than through water (Radisic et al., 2005; Brown et al., 2007). In scaffolds with a sufficiently large number of cells, the hindered diffusion of metabolites will be supplemented by their increased consumption. Therefore, in static conditions, where nutrients are distributed only by diffusion, areas in which cell proliferation 


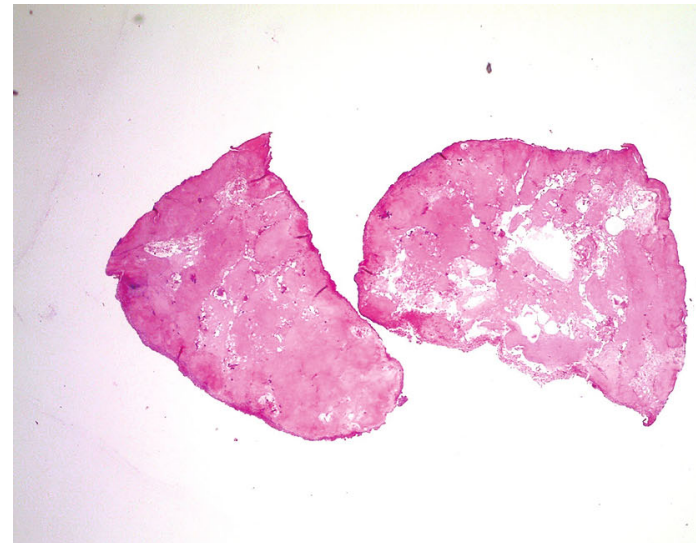

(a)

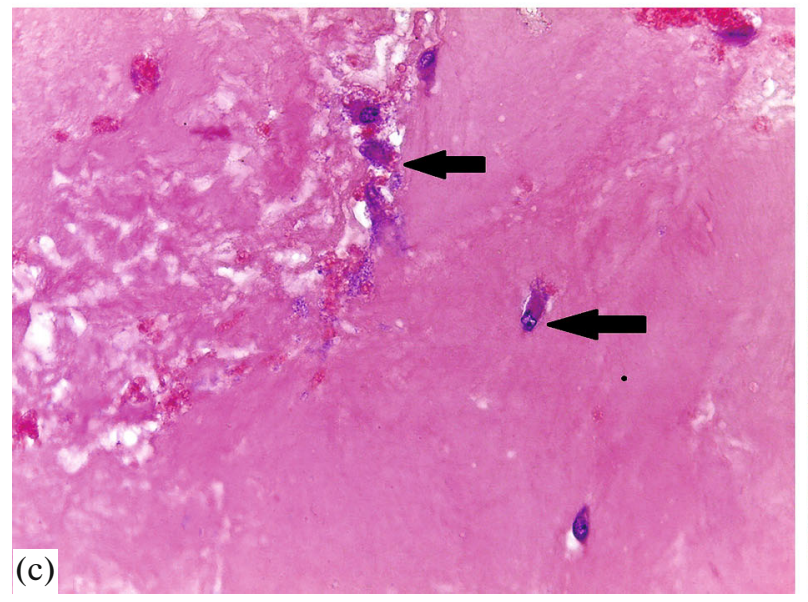

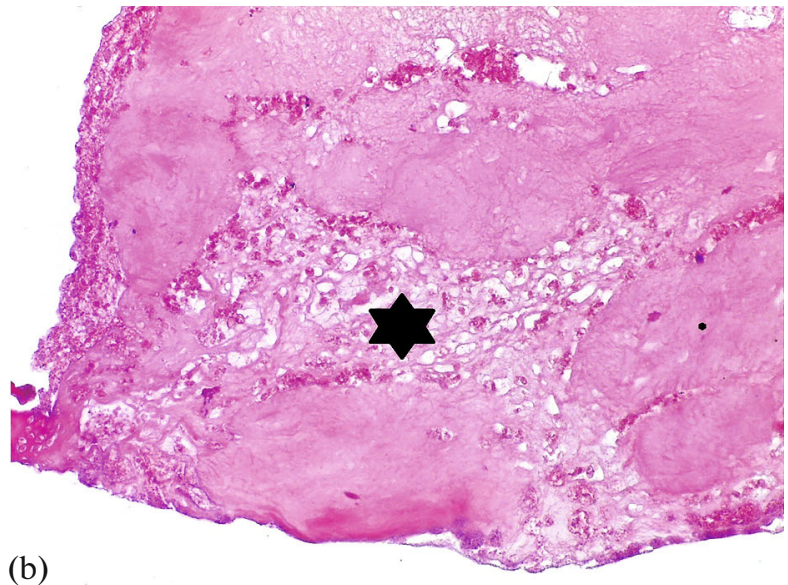

(b)

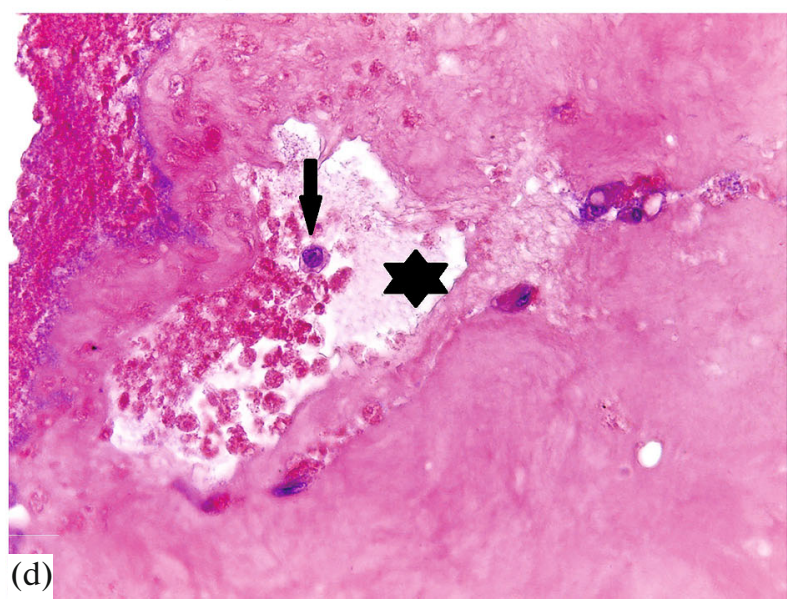

Fig. 4. The scaffolds in 28 days of incubation. Staining with hematoxylin and eosin. Arrows indicate living cells; $(*)$ Cell detritus. Ob.: (a) $2.5 \times$, (b) $10 \times$, (c, d) $40 \times$.
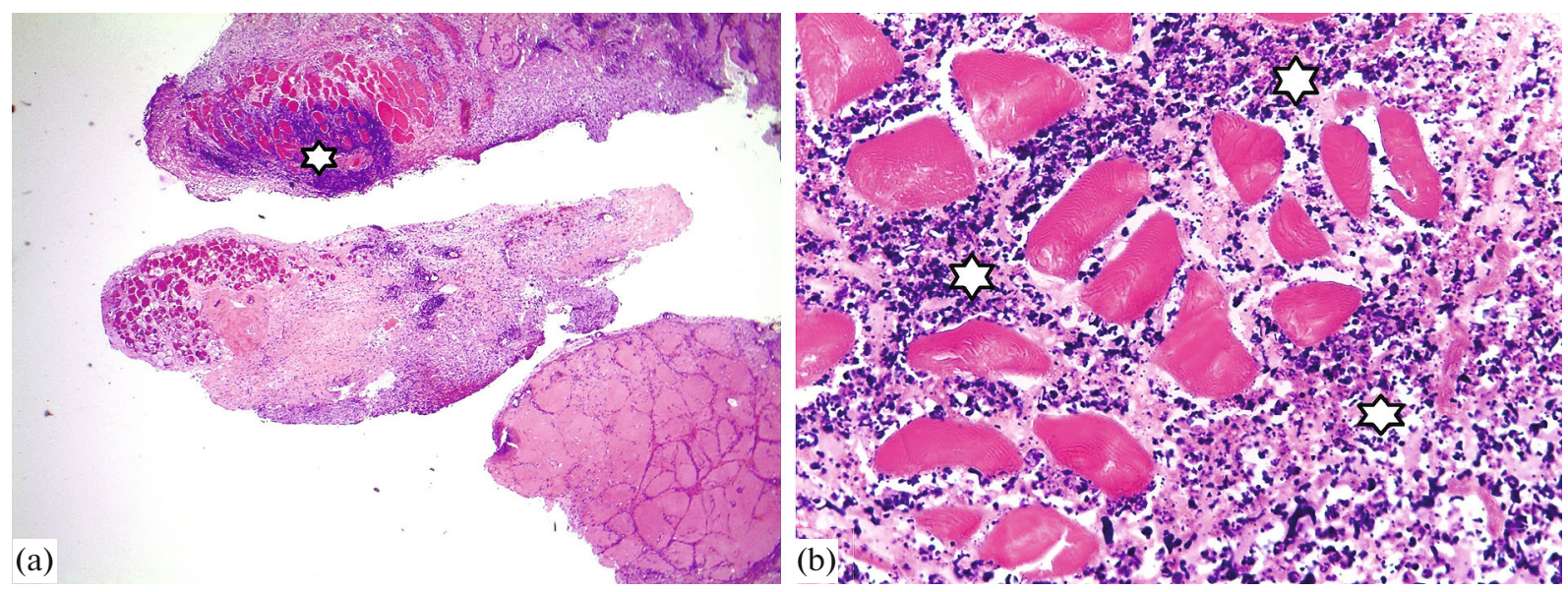

Fig. 5. The area of the scaffold implantation to rat in 2 weeks. (*) Iinflammatory response. Staining with hematoxylin and eosin. Ob.: (a) $2.5 \times$, (b) $40 \times$.

inevitably arise-the outer surface of the scaffold (Lewis et al., 2005).

The results obtained in our study are good illustrations of the issue described above. Already in 1 hour of the scaffolds incubation under the static conditions, the cells moved to the outer surfaces of the scaffold and air bubbles. Within the next few days a massive outflow of cells from collagen and their attachment to the bottom of the Petri dish was observed. Other authors have also reported on the heterogeneous dis- 


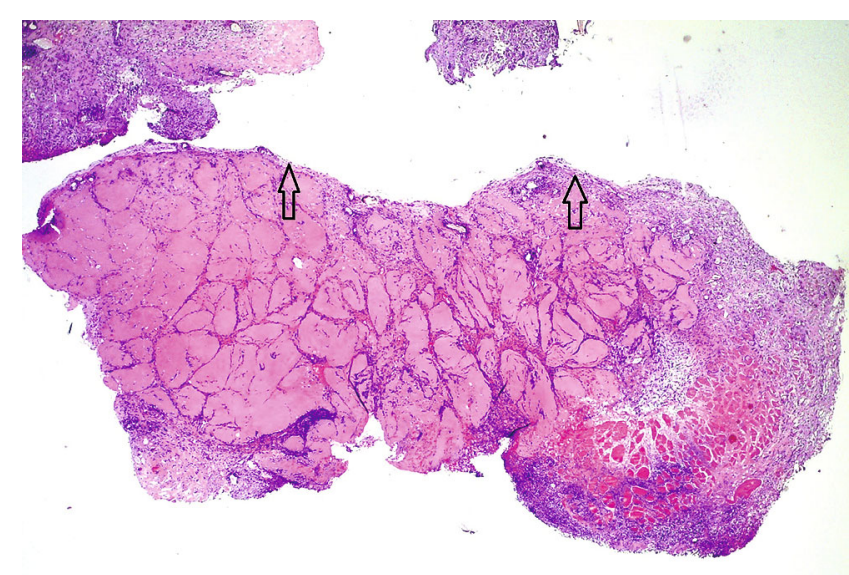

Fig. 6. Formation of a connective tissue capsule at the border of the scaffold with subcutaneous adipose tissue (indicated by arrows). Staining with hematoxylin and eosin. Ob. $2.5 \times$.

tribution of cells within scaffold. Thus, Lewis et al. (2005) observed an increase in the density of bovine chondrocytes in the peripheral layers of the porous terephthalate/polybutylene terephthalate scaffold during the first 14 days of cultivation. It was also reported (Radisic et al., 2005) that oxygen concentration and viability of rat cardiac myocytes decreased linearly and the density of living cells decreased exponentially with increasing of the distance from the structure surface.

Cartilage is an avascular tissue and the relatively slow diffusion of substances into the depth of the structure is not considered a predominant problem (Grogan et al., 2003). However, artificial scaffolds use a high density of cells to obtain more "functional" tissue, since it is critical for intercellular contacts estab- lishment and performance of the scaffold as a genuine cartilage (Radisic et al., 2005; Brown et al., 2007; Cigan et al., 2016). For the bioprinting, a high cell density is also required to achieve good survival after the printing (Nguyen et al., 2017). Thus, a contradiction arises between the high cell density and the sufficient oxygen content. This becomes especially important in the context of Okubo et al. findings (2019). In their opinion, the efficiency of chondrogenesis directly depends on the density of cells in scaffolds (the higher, the better) and the factor of high cell viability was more important than attempts to stimulate chondrogenesis.

In accordance with our data, when the scaffold was incubated for 4 weeks it was partially destroyed and compressed. One of the reasons that caused the destruction of collagen could be the secretion of proteolytic enzymes by cells (Zhang et al., 2019). Deformation and compression of structures made of natural materials, for example, extracellular matrix of cartilage or collagen itself, due to the vital activity of cells are also described in the literature (Liu et al., 2008; Rowland et al., 2013). Cell-mediated compression of the porous material can reduce the diffusion of oxygen and nutrients to the core of the scaffold, and, as a consequence, the volume available for cell proliferation (Rowland et al., 2013).

Drobnik et al. (2019) investigated the durability of three-dimensional spongy porous scaffolds based on collagen type I with or without neural rat embryonic cells in the case of implantation into rat brain. It was shown that the implants remained structurally intact for 4 weeks, but induced granulomatous inflammation, including the accumulation of multinuclear macrophages, mononuclear inflammatory cells, and the formation of blood vessels. The authors hypothesized that immune responses, including inflammation, oxidative stress, and low levels of trophic factors,
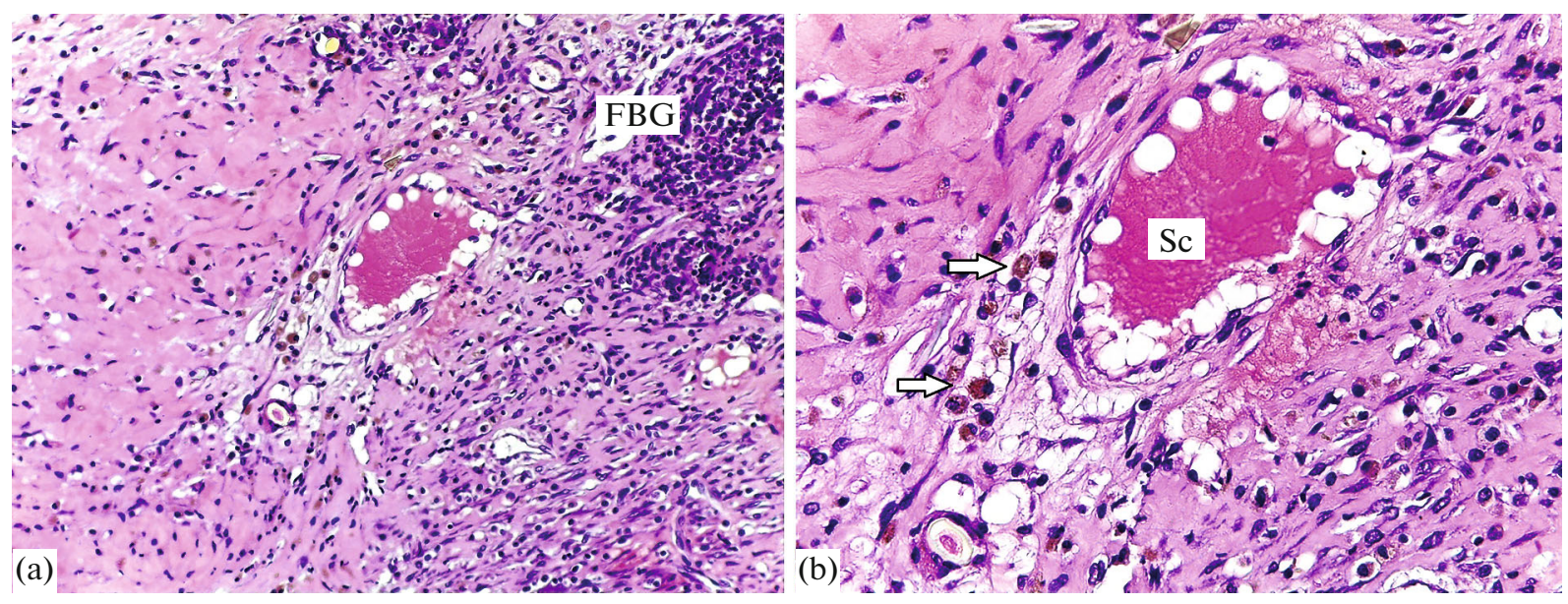

Fig. 7. Zone of scaffold resorption. (a) Macrophages and granulomas of foreign bodies in the zone of elimination of biomaterial; (b) the area at higher magnification. Sc-scaffold, FBG-foreign body granuloma, arrows indicate macrophages. Staining with hematoxylin and eosin. Ob.: $20 \times$, (b) $40 \times$. 

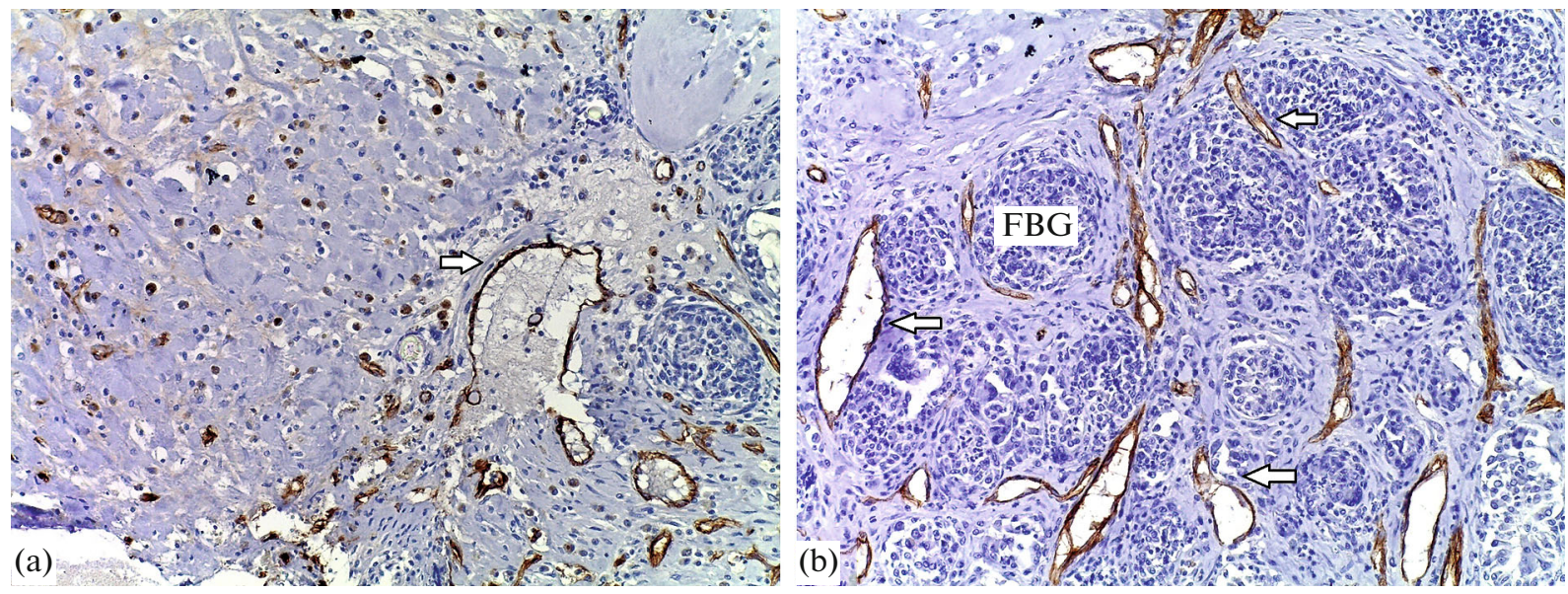

Fig. 8. Vascularization of the scaffold resorption zone. (a) Angiogenesis at the scaffold border; (b) angiogenesis in the area of foreign body granuloma formation (with multinucleated resorption cells). Arrows show the immunohistochemical reaction of the vascular endothelium with antibodies to CD31. Ob. $20 \times$.

may cause cell death within the scaffold. We observed a similar picture of inflammation after subcutaneous implantation of collagen scaffolds in rats. However, in our study, the scaffolds completely resolved within 4-6 weeks, probably due to the fact that they consisted of unmodified collagen. The detection of blood vessels invading the scaffold is positive, as vascularization is considered a critical development in tissue engineering (Murphy et al., 2020). Despite the present of viable cells corresponding by morphological criteria to young chondrocytes, the formation of cartilaginous tissue did not occur. This is probably both the result of the rapid resorption of collagen and the small number of surviving cells. The remaining cells did not have time to form their own matrix.

Considering its clinical use, cartilage scaffolds must be volumetric (not flat) and contain the physiological

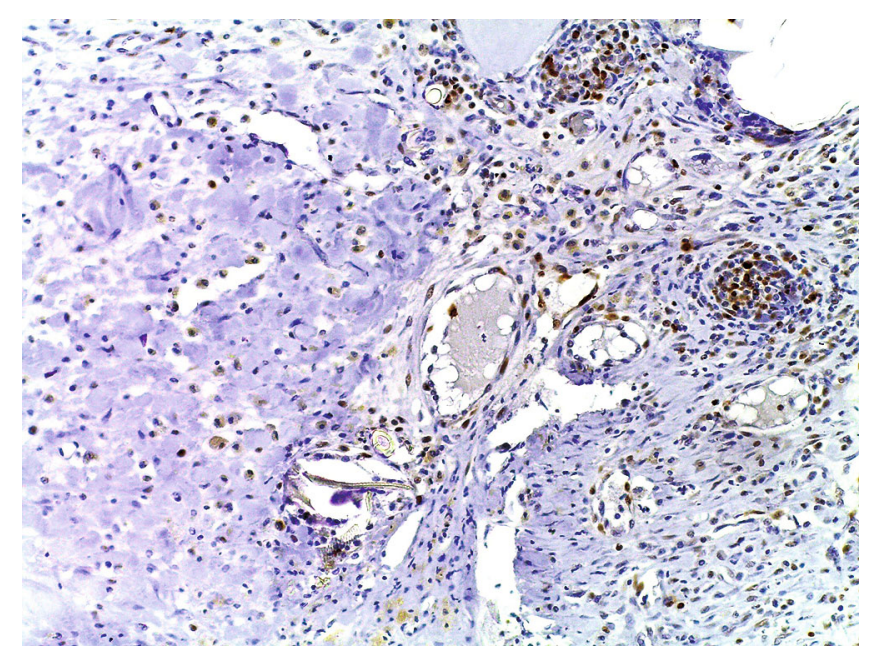

Fig. 9. Immunohistochemical reaction of cell nuclei with antibodies to PCNA in the scaffold resorption zone. Ob. $20 \times$. amount of metabolically active differentiated cells (Radisic et al., 2005). In the case of the scaffolds of more than $1 \mathrm{~mm}$ thickness, the supply of nutrients and especially oxygen to cells is a critical problem. Limitation of the diffusion of nutrients leads to spatially heterogeneous properties of the artificial tissue (Bian et al., 2009). Higher cell viability is achieved in less dense gels, in which diffusion is better (Nguyen et al., 2017; Okubo et al., 2019). However, in three-dimensional bioprinting, the density of the material must ensure the possibility of obtaining a stable structure of a given shape (outer geometry and internal structure) otherwise all the advantages of the technology will be ruined. This contradiction can be resolved by including additional channels and pores, for example, from sacrificial materials that are removed from the completed scaffolds (Levato et al., 2017), or by using dynamic cultivation systems (e.g., bioreactors). At the same time, there is an opinion that perfusion systems may not be suitable for obtaining cartilage, since they are capable of removing specific metabolites and causing to cell apoptosis (Grogan et al., 2003).

The results of our study showed that the inherent porosity of $4 \%$ collagen was insufficient to supply the incorporated cells with oxygen and nutrients and maintain their viability for a long time in vitro. The second drawback of the material was its rapid (within a month) degradation in the body of the animals. This, in turn, did not allow the necessary time to maintain conditions for the formation of cartilage at the implantation site.

\section{ACKNOWLEDGMENTS}

The authors would like to express their deep gratitude to Zaira Gadzhievna Dibirova, research assistant at the Laboratory of Radiation Pathomorphology, for invaluable assistance in carrying out the technical stages of histological studies. 

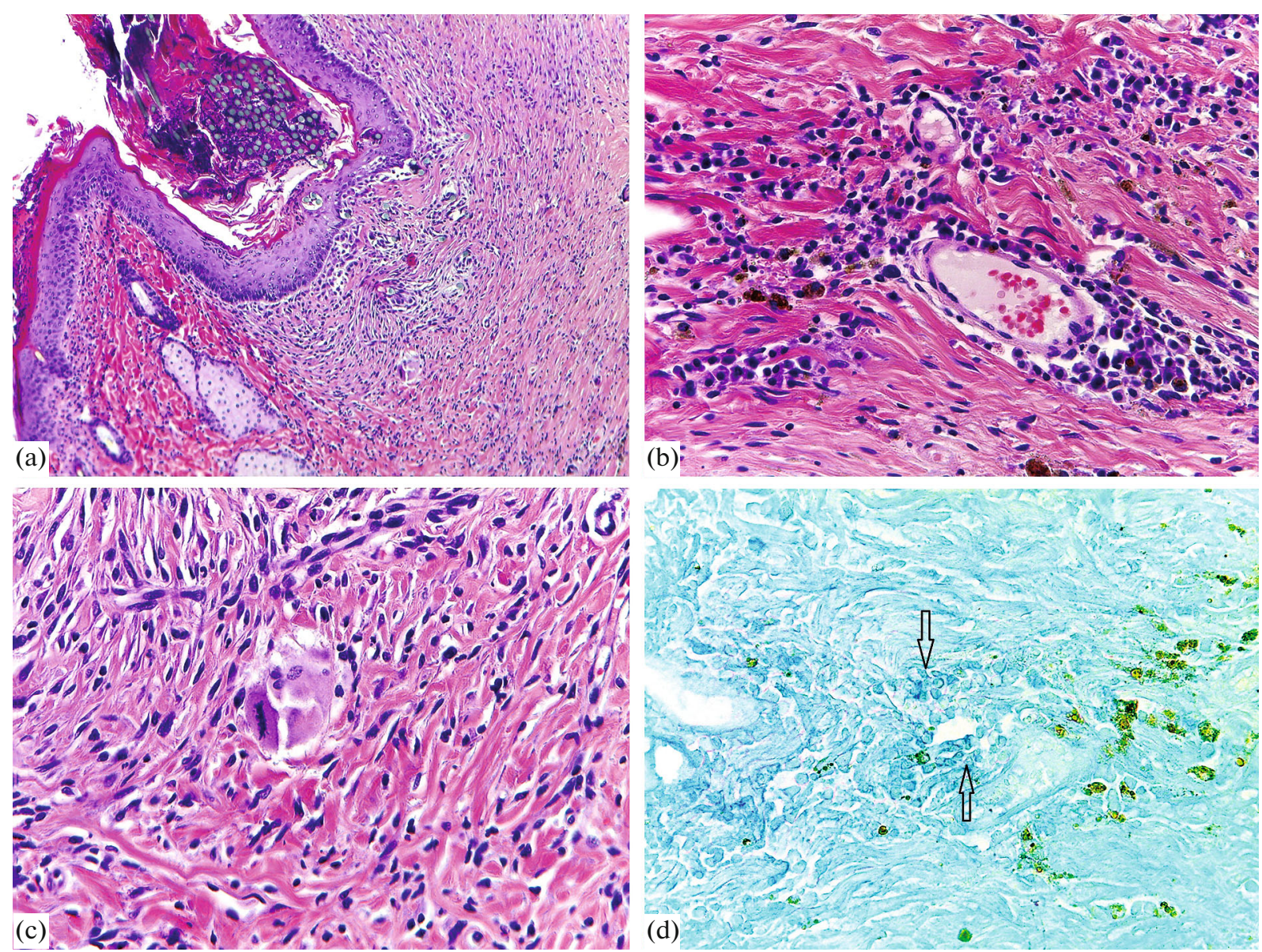

Fig. 10. Zone of scaffold implantation in 6 weeks. (a) In the upper left corner, a suture thread fragment is visible at the implantation site; (b, c) in the surrounding tissues, groups of small cells with rounded nuclei are visible, according to morphological criteria corresponding to young chondrocytes; (d) a group of cells with a positive reaction to glycosaminoglycans in the subcutaneous connective tissue of a rat (shown by arrows) in the zone of organic matrix resorption. $(\mathrm{a}-\mathrm{c})$ Staining with hematoxylin and eosin, (d) staining with alcian blue. Ob.: (a) $10 \times$, (b-d) $40 \times$.

\section{FUNDING}

This work was carried out within the framework of the implementation of the topics of the state assignment of the Ministry of Health of the Russian Federation for 2018-2020.

\section{COMPLIANCE WITH ETHICAL STANDARDS}

Conflict of interest. The authors declare that they have no conflict of interests.

Statement on the welfare of animals. The studies were carried out in accordance with the principles of the European Convention for the Protection of Vertebrate Animals for Experimental and Other Scientific Purposes (Strasbourg, 1986).

\section{OPEN ACCESS}

This article is licensed under a Creative Commons Attribution 4.0 International License, which permits use, sharing, adaptation, distribution and reproduction in any medium or format, as long as you give appropriate credit to the original author(s) and the source, provide a link to the Creative Commons licence, and indicate if changes were made. The images or other third party material in this article are included in the article's Creative Commons licence, unless indicated otherwise in a credit line to the material. If material is not included in the article's Creative Commons licence and your intended use is not permitted by statutory regulation or exceeds the permitted use, you will need to obtain permission directly from the copyright holder. To view a copy of this licence, visit ttp://creativecommons.org/licenses/by/4.0/.

\section{REFERENCES}

Abraham, L.C., Zuena, E., Perez-Ramirez, B., and Kaplan, D.L., Guide to collagen characterization for biomaterial studies, J. Biomed. Mater. Res. B Appl. Biomater., 2008, vol. 87 , p. 264.

https://doi.org/10.1002/jbm.b.31078

Arguchinskaya, N.V., Beketov, E.E., Osidak, E.O., Severyukov, F.E., Shegai, P.V., and Kaprin, A.D., Human thyroid cartilage scaffold fabrication using 3D-bioprinting, Genes Cells, 2019, vol. 14, p. 26.

Beketov, E.E. Isaeva, E.V., Shegai, P.V., Ivanov, S.A., and Kaprin, A.D., Current state of tissue engineering for carti- 
lage regeneration, Genes Cells, 2019, vol. 14, no. 2, p. 12. https://doi.org/10.23868/201906013

Bian, L., Angione, S.L., Ng, K.W., Lima, E.G., Williams, D.Y., Mao, D.Q., Ateshian, G.A., and Hung, C.T., Influence of decreasing nutrient path length on the development of engineered cartilage, Osteoarthritis Cartilage, 2009, vol. 17, p. 677.

https://doi.org/0.1016/j.joca.2008.10.003

Brown, D.A., MacLellan, W.R., Laks, H., Dunn, J.C.Y., Wu, B.M., and Beygui, R.E., Analysis of oxygen transport in a diffusion-limited model of engineered heart tissue, Biotechnol. Bioeng., 2007, vol. 97, p. 962.

https://doi.org/10.1002/bit.21295

Chaisri, P., Chingsungnoen, A., and Siri, S., Repetitive glyleu-lys-gly-glu-asn-arg-gly-asp peptide derived from collagen and fibronectin for improving cell-scaffold interaction, Appl. Biochem. Biotechnol., 2015, vol. 175, p. 2489.

https://doi.org/10.1007/s12010-014-1388-y

Cigan, A.D., Durney, K.M., Nims, R.J., Vunjak-Novakovic, G., Hung, C.T., and Ateshian, G.A., Nutrient channels aid the growth of articular surface-sized engineered cartilage constructs, Tissue Eng. Part A, 2016, vol. 22, p. 1063. https://doi.org/10.1089/ten.TEA.2016.0179

Cui, X., Breitenkamp, K., Finn, M.G., Lotz, M., and D'Lima, D.D., Direct human cartilage repair using threedimensional bioprinting technology, Tissue Eng. Part A, vol. 18, p. 1304.

https://doi.org/10.1089/ten.TEA.2011.0543

Drobnik, J., Pietrucha, K., Janczar, K., Polis, L., Polis, B., Safandowska, M., and Szymański, J., Intra-cerebral implantation of a variety of collagenous scaffolds with nervous embryonic cell, Exp. Ther. Med., 2019, vol. 18, p. 4758.

https://doi.org/10.3892/etm.2019.8116

Grogan, S.P., Rieser, F., Winkelmann, V., Berardi, S., and Mainil-Varlet, P., A static, closed and scaffold-free bioreactor system that permits chondrogenesis in vitro, Osteoarthritis Cartilage, 2003, vol. 11, p. 403.

https://doi.org/10.1016/s1063-4584(03)00053-0

Kesti, M., Eberhardt, C., Pagliccia, G., Kenkel, D., Grande, D., Boss, A., and Zenobi-Wong, M., Bioprinting complex cartilaginous structures with clinically compliant biomaterials, Adv. Funct. Mater., 2015, vol. 25, p. 7406.

https://doi.org/10.1002/adfm.201503423

Levato, R., Webb, W.R., Otto, I.A., Mensinga, A., Zhang, Y., van Rijen, M., van Weeren, R., Khan, I.M., and Malda, J., The bio in the ink: cartilage regeneration with bioprintable hydrogels and articular cartilage-derived progenitor cells, Acta Biomater., 2017, vol. 1, p. 41.

https://doi.org/10.1016/j.actbio.2017.08.005

Lewis, M.C., Macarthur, B.D., Malda, J., Pettet, G., and Please, C.P., Heterogeneous proliferation within engineered cartilaginous tissue: the role of oxygen tension, Biotechnol. Bioeng., 2005, vol. 91, p.607.

https://doi.org/10.1002/bit.20508

Liu, C.Z., Xia, Z.D., Han, Z.W., Hulley, P.A., Triffitt, J.T., and Czernuszka, J.T., Novel $3 \mathrm{~d}$ collagen scaffolds fabricated by indirect printing technique for tissue engineering, $J$. Biomed. Mater. Res. B Appl. Biomater., 2008, vol. 85, p. 519. https://doi.org/10.1002/jbm.b.30975

Malda, J., Woodfield, T.B., Vloodt, F.V., Kooy, F.K., Martens, D.E., Tramper, J., Blitterswijk, C.A, and Riesle, J.U., The effect of PEGT/PBT scaffold architecture on oxygen gradients in tissue engineered cartilaginous constructs, Biomaterials, 2004, vol. 25, p. 5773.

https://doi.org/10.1016/j.biomaterials.2004.01.028
Murphy, S.V. and Atala, A., 3D bioprinting of tissues and organs, Nat. Biotechnol., 2014, vol. 32, p. 773.

https://doi.org/10.1038/nbt.2958

Murphy, S.V., De Coppi, P., and Atala, A., Opportunities and challenges of translational 3D bioprinting, Nat. Biomed. Eng., 2020, vol. 4, p. 370.

https://doi.org/10.1038/s41551-019-0471-7

Nguyen, D., Hägg, D.A, Forsman, A., Ekholm, J., Nimkingratana, P, Brantsing, C., Kalogeropoulos, T., Zaunz, S., Concaro, S., Brittberg, M., Lindahl, A., Gatenholm, P., Enejder, A., and Simonsson, S., Cartilage tissue engineering by the 3D bioprinting of IPS cells in a nanocellulose/alginate bioink, Sci. Rep., 2017, vol. 7, p. 658. https://doi.org/10.1038/s41598-017-00690-y

Okubo, R., Asawa, Y., Watanabe, M., Nagata, S., Nio, M., Takato, T., Hikita, A., and Hoshi, K., Proliferation medium in three-dimensional culture of auricular chondrocytes promotes effective cartilage regeneration in vivo, Regen. Ther., 2019, vol. 15, p. 306.

https://doi.org/10.1016/j.reth.2019.10.002

Osidak, E.O., Karalkin, P.A., Osidak, M.S., Parfenov, V.A., Sivogrivov, D.E., Pereira, A.S., Gryadunova, A.A., Koudan, E.V., Khesuani, Y.D., Kasyanov, V.A., Belousov, S.I., Krasheninnikov, S.V., Grigoriev, T.E., Chvalun, S.N., Bulanova, E.A., et al., Viscoll collagen solution as a novel bioink for direct 3D bioprinting, J. Mater. Sci. Mat. Med., 2019, vol. 30, p. 31.

https://doi.org/10.1007/s10856-019-6233-y

Radisic, M., Malda, J., Epping, E., Geng, W., Langer, R., and Vunjak-Novakovic, G., Oxygen gradients correlate with cell density and cell viability in engineered cardiac tissue, Biotechnol. Bioeng., 2005, vol. 93, p. 332.

https://doi.org/10.1002/bit.20722

Ren, X., Wang, F., Chen, C., Gong, X., Yin, L., and Yang, L., Engineering zonal cartilage through bioprinting collagen type ii hydrogel constructs with biomimetic chondrocyte density gradient, BMC Musculoskelet. Disord., 2016, vol. 20 , p. 301 .

https://doi.org/10.1186/s12891-016-1130-8

Rowland, C.R., Lennon, D.P., Caplan, A.I., and Guilak, F., The effects of crosslinking of scaffolds engineered from cartilage ECM on the chondrogenic differentiation of MSCs, Biomaterials, 2013, vol. 34, p. 5802.

https://doi.org/10.1016/j.biomaterials.2013.04.027

Schuurman, W., Levett, P.A., Pot, M.W., Weeren, P., Dhert, W.J.A., Hutmacher, D.W., Melchels, F.P.W., Klein, T.J., and Malda, J., Gelatin-methacrylamide hydrogels as potential biomaterials for fabrication of tissue-engineered cartilage constructs, Macromol. Biosci., 2013, vol. 13, p. 551.

https://doi.org/10.1002/mabi.201200471

Skardal, A., Devarasetty, M., Kang, H.W., Mead, I., Bishop, C., Shupe, T., Lee, S.J., Jackson, J., Yoo, J., Soker, S., and Atala, A., A Hydrogel bioink toolkit for mimicking native tissue biochemical and mechanical properties in bioprinted tissue constructs, Acta Biomater., 2015, vol. 25, p. 24.

https://doi.org/10.1016/j.actbio.2015.07.030

Zhang, Y., Zhou, D., Chen, J., Zhang, X., Li, X., Zhao, W., and $\mathrm{Xu}, \mathrm{T}$., Biomaterials based on marine resources for 3D bioprinting applications, Mar. Drugs, 2019, vol. 17, p. 555. https://doi.org/10.3390/md17100555 